\title{
Latent class analysis of non-opioid dependent illegal pharmaceutical opioid users in Ohio
}

\author{
Robert G. Carlson ${ }^{1}$, Ramzi W. Nahhas ${ }^{2}$, Raminta Daniulaityte ${ }^{1}$, Silvia S. Martins ${ }^{3}$, Linna Li ${ }^{1}$, \\ and Russel Falck ${ }^{1}$ \\ ${ }^{1}$ Center for Interventions, Treatment, and Addiction Research, Department of Community Health, \\ Boonshoft School of Medicine, Wright State University, 3640 Colonel Glenn Highway, Dayton, \\ $\mathrm{OH} 45435$ \\ ${ }^{2}$ Division of Morphological Sciences and Biostatistics, Lifespan Health Research Center, \\ Department of Community Health, Boonshoft School of Medicine, Wright State University, 3171 \\ Research Boulevard, Dayton OH 45420 \\ ${ }^{3}$ Department of Epidemiology, Columbia University Mailman School of Public Health, New York, \\ NY 10032
}

\begin{abstract}
Background-Increases in non-medical use of pharmaceutical opioids in the U.S. have resulted in increases in opioid dependence and unintentional overdose deaths. We characterize heterogeneity in opioid use patterns among a community-based sample of 18-23 year-olds who use non-medical pharmaceutical opioids, yet are not opioid dependent.
\end{abstract}

Methods-Respondent-driven sampling recruited 390 participants. Latent class analysis stratified by racial/ethnic group identified subgroups of non-medical opioid users based on: sixmonth frequency of use; number of opioid disorder criteria; oral vs. non-oral administration; number of types of opioids used; use of CNS depressants while under using opioids; and reason for opioid use. Multinomial logistic regression estimated the significance of covariates in predicting class membership.

Results-Within whites and non-white groups, three classes emerged that were, generally, hierarchically ordered with respect to negative characteristics associated with non-medical opioid use. Within each group, the class with the least negative characteristics also had the highest proportion of individuals who use opioids only to self-medicate a health problem. Within each

(c) 2013 Elsevier Ireland Ltd. All rights reserved.

Corresponding Author: Robert G. Carlson; Center for Interventions, Treatment, and Addictions Research; Wright State University Boonshoft School of Medicine; 110 Medical Sciences Bldg.; 3640 Colonel Glenn Highway; Dayton, OH 45435 Tel: (937) 775-2066; Fax: (937) 775-2214; robert.carlson@wright.edu.

Publisher's Disclaimer: This is a PDF file of an unedited manuscript that has been accepted for publication. As a service to our customers we are providing this early version of the manuscript. The manuscript will undergo copyediting, typesetting, and review of the resulting proof before it is published in its final citable form. Please note that during the production process errorsmaybe discovered which could affect the content, and all legal disclaimers that apply to the journal pertain.

\section{Contributors}

R. Carlson, R. Falck, and R. Daniulaityte designed the study and wrote the protocol. R. Carlson wrote the first draft of the Introduction, non-statistical methods, parts of the results and discussion and made final edits. R. Daniulaityte revised sections of the Introduction, Results, and drafted the sections of the Discussion. R. Nahhas conducted statistical analyses, prepared tables and drafted the statistical methods and some results. L. Li maintained the database and prepared variables for analysis. Silvia Martins helped to design the statistical analyses and commented on the manuscript. R. Falck revised, edited, and commented on the penultimate draft of the paper. All authors contributed to and have approved the final manuscript.

Conflict of Interest

All authors declare that there are no conflicts of interest. 
group's three classes, a larger proportion who had $\geq 2$ opioid abuse and dependence disorder criteria always coincided with a larger proportion who use opioids $\geq 3$ days per week, a larger proportion who used CNS depressants while under the influence of opioids, and a smaller proportion who used opioids only to self-medicate.

Conclusion-Differences in patterns of opioid use within each racial/ethnic group of young people who are not opioid dependent suggest the need for tailored interventions designed to reduce the risk of transition to opioid dependence.

\section{Keywords}

non-medical pharmaceutical opioid use; latent class analysis

\section{INTRODUCTION}

Pharmaceutical opioids are medically valuable drugs that can be used to treat pain effectively, when prescribed and used appropriately (Yaksh and Wallace, 2011). Regardless, the non-medical use of pharmaceutical opioids has increased substantially in the United States since the late 1990s (Cicero et al., 2005; Drug Abuse Warning Network, 2003; Johnston et al., 2012). For example, from 2002 to 2010, past month non-medical use of pharmaceutical opioids increased from 4.1 to $4.5 \%$ among 18-25 year-olds (SAMHSA, 2011). The problem is manifest worldwide, including Canada, Australia, and parts of Europe (Fischer and Rehm, 2007; Hall and Farrell, 2011; Holmes, 2012).

In the United States, increases in non-medical pharmaceutical opioid use have resulted in increases in opioid dependence and unintentional overdose deaths (Centers for Disease Control and Prevention, 2011) and increasing risks of heroin initiation (Lankenau et. al., 2012; Peavy et al., 2012; Siegal et al., 2003). Simultaneously, the number of prescriptions for opioids has increased substantially (Manchikanti et al., 2010; Paulozzi and Ryan, 2006; Webster et al., 2011).

To develop effective public health interventions, more data are needed to better understand the heterogeneity of non-medical pharmaceutical opioid users (Zacny et al., 2003). Previous studies have described general characteristics, such as sources of opioid diversion (Inciardi et al., 2009), initiation into non-medical opioid use (Daniulaityte et al., 2006; Lankenau et al., 2012), motivations for opioid use (Boyd et al., 2006; McCabe et al., 2009), gender differences in non-medical opioid use (Simoni-Wastila et al., 2004), and HIV risk behaviors associated (Surratt et al., 2006). Other studies have used latent class analysis (LCA) to describe the heterogeneity of pharmaceutical opioid users using a range of different objectives and samples (national and treatment-based; Ghandour et al., 2008; Green et al., 2011; Monga et al., 2007; Vaughn et al., 2012).

This study describes heterogeneity in the pattern of non-medical pharmaceutical opioid use (henceforth referred to as "opioids") among a community-based sample of 18-23 year-olds who were not opioid dependent and had no history of heroin use or non-medical drug injection. We also examine how socio-demographic characteristics, use of other drugs, abuse of, or dependence on, other drugs, pain disorder, and psychiatric comorbidity are related to class membership (Ghandour et al., 2008). The study uses baseline data from our three-year natural history project designed to identify characteristics associated with transition to opioid dependence. 


\section{METHODS}

\subsection{Sample recruitment}

Respondent-driven sampling (RDS) was used to recruit 390 participants in the Columbus, Ohio, area between April 2009 and May 2010 (Heckathorn, 1997; 2002). Standard RDS methods were used, including limiting referrals to three per eligible person and compensating referrers $\$ 15$ for each person presenting at the project office for an eligibility determination (Wang et al., 2005; 2007). Our use of RDS is described in Daniulaityte and colleagues (2012).

\subsection{Eligibility}

Eligibility included: 1) being 18-23 years old; 2) self-reporting the non-medical use of pharmaceutical opioids on five or more occasions in the previous 90 days; 3 ) expressing intentions to use pharmaceutical opioids again; 4) residence in the Columbus, $\mathrm{OH}$, metropolitan area; and 5) identifying opioids s/he reported having used on a pill card similar to the one used in the National Survey on Drug Use and Health (NSDUH) (Caviness et al., 2006), except that the card did not have the drug names listed, to help verify the reported use of opioids. Young adults were deemed ineligible if they met DSM-IV criteria for lifetime opioid dependence, as ascertained with the DSM-IV Checklist (Forman et al., 2004; Hudziak et al., 1993), reported heroin use or any illicit injection drug use, had pending criminal charges, or were involved in formal substance abuse treatment.

\subsection{Data collection and measures}

Baseline structured questionnaires were administered by trained interviewers in private offices following completion of an informed consent. Protocols were approved by the Wright State University IRB. The baseline questionnaire was largely a computer-assisted, interviewer-administered instrument. Participants were compensated $\$ 50$ for completing a 1.5-2.5 hour baseline interview.

The questionnaire collected data in a number of areas, including six-month frequency of use of various drugs. Lifetime opioid abuse and dependence were assessed using the DSM-IV checklist. The computerized version of the Diagnostic Interview Schedule (CDIS) was used to ascertain lifetime abuse and dependence on other drugs, mental health disorders and pain disorder (Robins et al., 1999).

Frequency of drug use was collected through author-generated items employed in previous studies (Carlson et al., 2005; Falck et al., 2005; Siegal et al., 1998). The frequency of drug use question was: "During the past six months, how often did you use [drug]?" Response options ranged from "never/none" to "daily" use. For opioids, responses were collapsed to: " $\leq 1$ days/week" ("low level of use"); "about two days/week;" (corresponding roughly to "weekend use"); and $\geq 3$ days per week ("greater use"). Other drugs were collapsed to "Yes/ No." Opioid abuse and dependence disorder criteria were collapsed to $<2$ versus $\geq 2$. Route of administration was captured by asking: "In the past six months, how did you most often use [drug]?" collapsed to oral/non-oral. Number of different types of opioids used was ascertained by asking if participants had used 12 different opioid types, ranging from hydrocodone to oxymorphone. Number of types of opioids used were collapsed to $\leq 2$ versus $>2$. To determine the number of lifetime legitimate opioid prescriptions, we asked: "Have you ever received a prescription for "pain pills" for a health problem you experienced, like dental pain, broken bones, back pain, or after surgery?" Followed by: 'In the past six months, how many times have you been prescribed "pain pills" for a "legitimate" health problem?' To determine concurrent use of opioids and alcohol or tranquilizers, we asked: "In the past 6 months, how often did you use [drug] when you were 
under the influence of "pain pills?" Response options were categorized as "sometimes" versus "never." Reasons for opioid use were captured by asking: "In the past 6 months, did you use 'pain pills' illicitly to get 'high' " and/or "to self-medicate a health problem?"

\subsection{Statistical analysis}

Descriptive statistics (mean and SD, $\mathrm{n}$ and \%) for all variables were compared across ethnic/ racial groups using t-tests for continuous variables and chi-square tests for categorical variables (Fisher's exact test was used when any cell counts were $\leq 5$ ).

Latent class analysis (Lazarsfeld and Henry, 1968; Magidson and Vermunt, 2004) was used to identify subgroups of opioid users that were heterogeneous with respect to the latent construct, "pattern of non-medical use of opioids." The significance of demographic covariates (age, years since first non-medical use of pain pills, gender, education, employment, financial resources, relationship status, and residence status) as predictors of latent class membership were tested using multinomial logistic regression after the LCA was fit using the 3-step procedure, which takes into account the uncertainty in assigning latent class membership to individuals (Vermunt 2010, Asparouhov and Muthén, 2012). Interactions for pairs of significant covariates were tested as well. Hypothesis tests were conducted at the 0.05 level of significance. Means and proportions of all covariates and auxiliary variables were then compared across classes using posterior probability-based multiple imputations (Asparouhov, 2007).

Latent class indicators of "patterns of non-medical opioid use" included: six-month frequency of use; number of opioid abuse and dependence disorder criteria ( $<2$ versus $\geq 2)$; oral versus non-oral administration; number of different types of opioids used ( $\leq 2$ versus $>$ 2); use of CNS depressants (alcohol or tranquilizers) while under the influence of opioids (yes/no); and reason for opioid use ("to get high" only; to "self-medicate" only; or both). Decisions regarding which variables to include as latent class indicators were made based on goodness of fit of the LCA model. Some auxiliary variables we considered for inclusion as indicators of the latent construct (e.g., most common source of opioids, ever had a legitimate opioid prescription, ever sold opioids) were too highly correlated with the other indicators, resulting in a violation of the local independence assumption; therefore, these were excluded from indicators. Whether and how to collapse categories was based on model interpretability. In general, binary variables were preferred and categories were collapsed to have approximately equal counts in each level, although this was not always possible. Frequency of opioid use was collapsed to three levels, since a binary split was felt to oversimplify this variable.

Preliminary analyses demonstrated that there was a lack of measurement invariance between ethnic/racial groups (non-whites vs. whites). That is, ethnic/racial groups differed not only quantitatively in terms of their proportions of individuals in different classes, but also qualitatively - the pattern of large and small within-class conditional probabilities of the latent class indicators differed between groups. Therefore, distinct LCAs were carried out for non-whites and whites. For each LCA, we first fit models with differing numbers of classes. The choice of the optimal number of classes was based on: a) the statistical criteria Akaike's Information Criterion (AIC), Bayesian Information Criterion (BIC), and the Bootstrap Likelihood Ratio Test (BLRT); b) latent class separation; c) homogeneity; d) local independence; and e) interpretability (Collins and Lanza, 2010). Lower AIC and BIC are preferred, as is a BLRT p-value $<0.05$ (indicating rejection of the null hypothesis that a K-1 class model is sufficient where the alternative hypothesis is that a $\mathrm{K}$ class model is necessary). Latent class separation and homogeneity are subjective judgments about the distinctness (between classes) of the conditional distributions of the indicators and about the similarity of response patterns between individuals within classes, respectively. Latent class 
separation is greatest when response patterns with high probability in one class have low probability in other classes. Homogeneity is greatest when, within a class, all conditional probabilities are either 0 or 1 (Collins and Lanza, 2010). Local independence states that the indicators are independent given the latent classes and is the primary assumption of an LCA. Within-class pairwise independence was assessed by computing bivariate residuals and then summarizing them as a bivariate chi-square statistic (BVCS). A BVCS > 2 indicates that the local independence assumption may be violated for that pair of indicators.

Latent class prevalences were computed based on estimated posterior probabilities, not simply based on each individual's most likely class membership. The LCA, the multinomial logistic regression, and the comparison of means and proportions across classes were carried out simultaneously in Mplus 7 (Muthén and Muthén, 2012).

\section{RESULTS}

\subsection{Socio-demographic characteristics and indicator, covariate, and auxiliary variable distributions}

Socio-demographic characteristics, covariates, and auxiliary variables overall and by ethnic/ racial grouping (referred to as "group") are presented in Table 1. The mean age was 21.0 years, and $54.6 \%$ were men. Whites (192) constituted $49.2 \%$ of the sample; among the 198 non-whites, 88.4\% were African American, 3.0\% Hispanic/Latino, 3.0\% Asian/Pacific Islander, 5.1\% were biracial (African American/other), and one was Somali/white.

On average, participants had been using opioids non-medically for about four years, with a mean age of initiation of 16.9 years. In the previous six months, immediate-release oxycodone products were the most commonly used opioids ( $92.3 \%)$, followed by hydrocodone (83.6\%), oxycodone (29.0\%), codeine (25.9\%), morphine (7.7\%), "other pain medication" (7.7\%), hydromorphone (6.7\%), methadone (6.4\%), buprenorphine/naloxone sublingual (4.4\%), fentanyl (1.3\%), and oxymorphone (0.3\%). Indicator variables and their descriptions are presented in Table 2.

White and non-white groups differed on a number of variables (Tables 1 and 2). For example, six-month frequency of opioid use and the proportion administering opioids orally was greater among non-whites ( $\mathrm{p}<0.001$; Table 2$)$. The proportions of individuals who used more than two kinds of opioids $(\mathrm{p}=0.003)$ and who used opioids and other CNS depressants were greater among whites $(\mathrm{p}=0.016)$.

\subsection{Optimal number of latent classes}

Model selection criteria did not unanimously point to the same optimal number of classes. For both groups, the four-class model was ruled out based on higher (worse) AIC and BIC, and failure of the BLRT to reject the null hypothesis that a three-class model is sufficient. For both groups, the three-class model was preferred to the two-class model based on better adherence to the local independence assumption, with only two BVCS $>2$ for the three-class model for whites and no BVCS $>2$ for the three-class model for non-whites, but 4 (whites) or 2 (non-whites) pairs of indicators exhibiting a BVCS $>2$ for each of the two-class models. Additionally, the three-class models exhibited adequate latent class separation and homogeneity and were highly interpretable. Therefore, the three-class models were chosen.

\subsection{Conditional probabilities of latent class indicators and latent class definitions}

The within-class distributions of the latent class indicators are shown in Table 3, by ethnic/ racial group. The within-group class numbering (1 to 3 ) reflects a rough ordering of the 
groups from most to least negative pattern of opioid use. Individual conditional probabilities differ between groups, and their joint distributions differ markedly.

Among non-whites, Class NW-1 has more negative characteristics, with larger proportions of individuals having a high frequency of opioid use, having $\geq 2$ opioid disorder criteria, who have used $>2$ different kinds of opioids, and who have used CNS depressants with opioids. Not all those in Class NW-1 have a high frequency of use, however, with $27 \%$ using $<2$ days per week. Class NW-2 is characterized by having a large proportion (87\%) of individuals who use opioids about two days per week, and low proportions with $\geq 2$ opioid disorder criteria or use of other CNS depressants with opioids. Class NW-3 is characterized by the least negative characteristics, with $100 \%$ using opioids < 2 days per week, none with $\geq 2$ opioid disorder criteria, and little use of CNS depressants with opioids. Almost everyone in the NW classes used opioids orally.

Class W-1 is similar in some ways to Class NW-1 with generally more negative characteristics than the other white classes. Class W-1 is distinguished from the other classes by having the lowest proportion using $<2$ days per week, highest proportion with $\geq 2$ opioid abuse and dependence disorder criteria, highest proportion using other CNS depressants with opioids, and 100\% reporting use to "get high and self-medicate." Class W-2 has a mix of individuals who use opioids $<2$ days per week $(62 \%)$ and individuals who use opioids $\geq$ 3 days per week (29\%). Rather than being distinguished by frequency of use, Class W-2 is characterized by having a very low proportion $(30 \%)$ of individuals who use opioids orally, a high proportion using more than two different kinds of opioids, a high proportion who use CNS depressants while under the influence of opioids, and 99\% using opioids to get high only. Class W-3 is characterized by having the least negative characteristics, including low frequencies of opioid use, a low proportion with $\geq 2$ opioid disorder criteria, and almost all reporting oral opioid use.

\subsection{Predictors of latent class membership}

Based on the results of the multinomial logistic regression, the significant predictors of latent class membership were age (both groups) and education (whites only; Table 4). The age $\times$ education interaction was not significant.

\subsection{Comparison of covariates and auxiliary variables between classes}

Compared to other NW classes, participants in Class NW-1 had a significantly larger mean number of days drunk in the previous 30 days, larger proportions having mental health disorders, higher proportions using other drugs such as marijuana and MDMA, and higher proportions having alcohol abuse or dependence or marijuana dependence (Table 5). Within each group, the class with the least negative characteristics (NW-3 and W-3) had higher proportions who obtained opioids for free or left over from legitimate prescriptions, although this difference was only significant within whites. In other words, individuals in classes with more negative characteristics were more likely to buy or steal opioids from others or "doctor shop."

Among whites, participants in class W-2 were more likely to use several other substances (Table 5). The white classes differed significantly in their proportions of individuals with pain, with almost $90 \%$ of those in Class W-1 (the class with $100 \%$ using to self-medicate) reporting having pain. Proportions reporting having pain were high regardless of group or class, ranging from $75 \%$ to $83 \%$ among non-whites and $69 \%$ to $89 \%$ among whites. However, classes within groups did not differ significantly in having pain disorder. 


\section{DISCUSSION}

Our findings indicate that the pattern of non-medical use of opioids among non-opioid dependent young adults varied both between and within ethnic/racial groups. Within each group, we found three subgroups that were, in general, hierarchically ordered with respect to negative characteristics associated with opioid use. Within each group, the class with the least negative characteristics (NW-3 and W-3) is also the class which has the highest proportion of individuals who use opioids only to self-medicate a health problem. Within each group's three classes, a larger proportion who have $\geq 2$ opioid disorder criteria always coincided with: a larger proportion who use opioids $\geq 3$ days per week, a larger proportion who used other CNS depressants while under the influence of opioids, and a smaller proportion who use only to self-medicate (and almost always coincided with a larger proportion who used more than two types of opioids). Between groups, however, there were differences in the distinctions between class characteristics and frequency.

Interestingly, almost all the non-whites administered opioids orally, while there was some variation among whites. Class W-2 had the highest rate of non-oral opioid administration (snorting) and also had the highest proportion of individuals using opioids to get high only. Non-whites had no group with these characteristics. Higher proportions of snorting opioids among whites is consistent with higher proportions reporting cocaine and other stimulant use, which are often snorted.

Those who were older (both groups) were more likely to be in classes having more negative characteristics (NW-1; W-1). Although not statistically significant, those in classes with more negative characteristics had been using opioids to get high for a longer period of time, as expected.

Comparison of covariates and auxiliary variables across the latent classes provides additional insight into the differences between these classes, although we are unable to ascribe causality in either direction (Table 5). For example, we cannot conclude that poorer mental health causes increased non-medical opioid use or vice versa, only that such an association was observed among non-whites in our sample. Unlike one prior study finding gender to be an important factor in predicting characteristics of opioid users (Wu et al., 2010; Green et al., 2011), gender had no significant association with the identified classes.

The illegal use of opioids coupled with other CNS depressants, like alcohol and benzodiazepines, can be life-endangering (e.g., Jones et al., 2012). Members of classes NW-1 as well as W-1 and W-2 had high proportions of concomitant use of opioids and CNS depressants placing them at high risk of potential overdoses.

Our findings contrast substantially with other studies of opioid users, in part, by the comparatively high representation of non-whites, the vast majority of whom were African American. Based on prior literature, we did not anticipate recruiting a high proportion of African Americans, but our assessment of RDS (Daniulaityte et al., 2012) suggests a high level of in-group recruitment among whites and African Americans, suggesting high levels of social distance. Importantly, this social distance is validated by our LCA that found significant "qualitative" differences between whites and non-whites. Findings indicate there may, in fact, be more nonmedical pharmaceutical opioid use among young African Americans than previously indicated by national epidemiologic monitoring, at least in the study location.

In a study with college students, McCabe and colleagues (2009) found that self-treatment of pain was more prevalent among African Americans, while recreational use was more common among white opioid users. Overall, ethnic/racial groups in our study did not differ 
in motivations for use (Table 2). However, in our study, which was not limited to college students, among whites, higher education was a predictor of being more likely to be in class W-2 compared to W-3, and class W-2 was comprised almost entirely of individuals who use opioids only to get high (recreational use as defined by McCabe and colleagues (2009).

McCabe and colleagues (2009) hypothesized that using opioids to self-treat pain would be associated with fewer substance abuse problems, compared to recreational (equivalent of our "to get high" category) or "mixed" (recreational and self-treatment) users. This was supported in their study, and was supported in ours, as well. Among whites and non-whites, the classes with the highest proportion of individuals who use opioids only to self-medicate (NW-3 and W-3) had the least negative characteristics associated with opioid use. Also, consistent with their study, members of classes NW-1, W-1, and W-2 who used opioids to get high or to get high and self-medicate, also had higher levels of negative characteristics as McCabe and colleagues (2009) hypothesized. The significance of reasons for opioid use reinforces prior suggestions of the need for population-based epidemiological surveys to differentiate non-medical pharmaceutical opioid users by their motivations of use, which could influence intervention approaches (Zacny and Lichtor, 2008).

Regardless of group or class, proportions of members reporting having pain in our study were consistently high, ranging from $69 \%$ to $89 \%$, although Class W-1 had significantly higher levels of pain, compared to Classes W-2 and W-3. High levels of having pain across classes may explain why proportions having pain disorder did not differentiate subgroups. Passik and colleagues (2006) also found a high proportion of prescription drug users $(\mathrm{n}=109)$ having pain $(76 \%)$ upon entering substance abuse treatment in Kentucky. In a study of 237 community-based opioid users recruited in Maine (Heimer et al., 2012), 40\% reported pain that interfered with their daily lives. We need to further differentiate the reasons participants in our study reported having pain.

Findings from other LCA analyses of opioid users differ substantially from ours because of differences in samples and study objectives. However, some similarities are noted. Based on NSDUH data, one study used LCA to identify heterogeneity of risk among 1,783 adolescents (12-17 years) reporting lifetime use of non-medical opioids (Vaughn et al., 2012). The four classes identified were generally hierarchically ordered with respect to levels of risk and substance use (although quite different indicators were used). While we also found a hierarchical ranking of classes with respect to negative characteristics associated with opioid use among classes, our study is based on young adults who were actively involved with non-medical use of opioids. In addition, Vaughn and colleagues (2009) found that African Americans were more likely than whites to be members of a high delinquency and low substance use class but less likely to be members of a high risk and high substance use/low delinquency class. In contrast, Class NW-1 is characterized by high frequencies of opioid and other drug use and negative characteristics associated with opioid use.

Limitations are noted. Our study was conducted in the Midwest U.S., so the findings may not be generalizable to other areas. Second, we attempted to make the sample as representative as possible by using respondent-driven sampling, but it may contain biases, including those related to employment and income levels. In addition, we lack a reliable measure of socioeconomic status; the recruited sample was very young, and some participants were still financially dependent on their families, making assessment complicated. Third, the age range of the sample was limited to 18-23 year-olds to capture those who arguably are at greater risk for opioid misuse and at risk of transition to dependence. Fourth, the use of a geographic indicator auxiliary variable may have provided some insight into the class distinctions, but we lack one that is meaningful. Finally, the 
findings are based on self-report, but there is substantial support for the validity of selfreport data (Adair et al., 1995; Darke, 1998).

In summary, our study provides new information about the heterogeneity of illicit opioid users who represent an age group (18-23) with the highest rates of illicit opioid use. Since our study focused on a community-based sample of non-medical users who were not opioid dependent (DSM-IV) and non-injectors, study findings can help tailor early interventions to address the unique needs and differential levels of risks associated with illicit opioid use. Young, non-dependent illicit pharmaceutical opioid users are an important population for interventions designed to reduce the risk of transition to opioid dependence, possible transition to heroin use, and unintentional overdose death. Future studies will identify characteristics associated with increases in opioid dependence criteria and transition to heroin, over three years.

\section{Acknowledgments}

The authors thank project participants, and site coordinators/interviewers Brooke Miller and Pamela Malzahn and interviewer Tim Lane, for their contributions.

\section{Role of Funding Source}

This study was supported by The National Institute on Drug Abuse, Grant No. R01DA023577. The content is solely the responsibility of the authors and does not necessarily represent the official views of the National Institute on Drug Abuse or the National Institutes of Health.

\section{REFERENCES}

Adair EBG, Craddock SG, Miller HG, Turner CF. Assessing consistency of responses to questions on cocaine use. Addiction. 1995; 90:1497-1502. [PubMed: 8528035]

Asparouhov, T. Wald test of mean equality for potential latent class predictors in mixture modeling. In: Muthén, LK.; Muthén, BO., editors. Technical appendix. Mplus User' Guide. Sixth Edition.. Los Angeles, CA: Muthén \& Muthén; 2007.

Asparouhov T, Muthén B. Auxiliary variables in mixture modeling: a 3-step approach using Mplus. Mplus Web Notes No. Oct 4.2012 15(Version 5)

Boyd CJ, McCabe SE, Teter CJ. Medical and nonmedical use of prescription pain medication by youth in a Detroit-area public school district. Drug Alcohol Depend. 2006; 81:37-45. [PubMed: 16040201]

Carlson RG, Wang J, Falck RS, Siegal HA. Drug use practices among mdma/ecstasy users in Ohio: a latent class analysis. Drug Alcohol Depend. 2005; 79:167-179. [PubMed: 16002026]

Caviness, LL.; Cunningham, DB.; Gibson, L.; Granger, RA.; Liu, S.; Martin, P.; McKamey, AC.; Morton, K.; Myers, SK.; Payne, S.; Piper, L.; Riggsbee, BH. National Survey on Drug Use and Health, 2005. Research Triangle Park, NC: RTI International; 2006.

Centers for Disease Control and Prevention. Vital Signs: Overdoses of prescription opioid pain relievers-United States, 1999-2008. MMWR. 2011; 60:1487-1492. [PubMed: 22048730]

Cicero TJ, Inciardi JA, Munoz A. Trends in abuse of OxyContin and other opioid analgesics in the United States: 2002-2004. J. Pain. 2005; 6:662-672. [PubMed: 16202959]

Collins, LM.; Lanza, ST. Latent Class and Latent Transition Analysis: With Applications in the Social, Behavioral, and Health Sciences. Hoboken: Wiley; 2010.

Daniulaityte R, Carlson RG, Kenne DR. Initiation to pharmaceutical opioids and patterns of misuse: preliminary qualitative findings obtained by the Ohio substance abuse monitoring network. J. Drug Issues. 2006; 36:787-808.

Daniulaityte R, Falck R, Li L, Nahhas R, Carlson RG. Respondent-driven sampling to recruit young adult non-medical users of pharmaceutical opioids: problems and solutions. Drug Alcohol Depend. 2012; 121:23-29. [PubMed: 21885213] 
Darke S. Self-report among injecting drug users: a review. Drug Alcohol Depend. 1998; 51:253-263. [PubMed: 9787998]

Drug Abuse Warning Network. Trends in Drug-Related Emergency Department Visits, 1994-2002 at a Glance. Rockville, MD: Substance Abuse and Mental Health Services Administration, Office of Applied Studies; 2003.

Falck RS, Siegal HA, Wang J, Carlson RG, Draus PJ. Non-medical drug use among adults in small towns in rural Ohio. J. Subst. Abuse Treat. 2005; 28:341-349. [PubMed: 15925268]

Fischer B, Rehm J. Illicit opioid use in the 21st century: witnessing a paradigm shift? Addiction. 2007; 102:499-550. [PubMed: 17362281]

Forman RF, Svikis D, Montoya ID, Blaine J. Selection of a substance use disorder diagnostic instrument by the national drug abuse treatment clinical trials network. J. Subst. Abuse Treat. 2004; 27:1-8. [PubMed: 15223087]

Ghandour LA, Martins SS, Chilcoat HD. Understanding the patterns and distribution of opioid analgesic dependence symptoms using a latent empirical approach. Int. J. Methods Psych. Res. 2008; 17:89-103.

Green TC, Black R, Grimes Serrano JM, Budman SH, Butler SF. Typologies of prescription opioid use in a large sample of adults assessed for substance abuse treatment. PLoS One. 2011; 6:e27244. [PubMed: 22087270]

Hall WD, Farrell MP. Minimising the misuse of oxycodone and other pharmaceutical opioids in Australia. Med. J. Aust. 2011; 195:248-249. [PubMed: 21895579]

Heckathorn D. Respondent-driven sampling: a new approach to the study of hidden populations. Soc. Probl. 1997; 44:174-199.

Heckathorn D. Respondent-driven sampling II: deriving valid population estimates from chain-referral samples of hidden populations. Soc. Probl. 2002; 49:11-34.

Heimer R, Dasgupta N, Irwin KS, Kinzley M, Harvey AP, Givens A, Grau L. Chronic pain, addiction severity, and misuse of opioids in Cumberland County, Maine. Addict. Behav. 2012; 37:346-434. [PubMed: 22138379]

Holmes D. Prescription drug addiction: the treatment challenge. Lancet. 2012; 379:17-18. [PubMed: 22232799]

Hudziak JJ, Helzer JE, Wetzel MW, et al. The use of the DSM-III R checklist for initial diagnostic assessments. Compr. Psychiatry. 1993; 34:375-383. [PubMed: 8131381]

Inciardi JA, Surratt HL, Cicero TJ, Beard RA. Prescription opioid abuse and diversion in an urban community: the results of an ultra-rapid assessment. Pain Med. 2009; 10:537-548. [PubMed: 19416440]

Johnston, LD.; O’Malley, PM.; Bachman, JG.; Schulenberg, JE. Institute for Social Research. Ann Arbor: The University of Michigan; 2012. Monitoring the Future National Survey Results on Drug Use, 1975-2011: Volume I, Secondary School Students.

Jones JD, Mogali S, Comer SD. Polydrug abuse: a review of opioid and benzodiazepine combination use. Drug Alcohol Depend. 2012; 125:8-18. [PubMed: 22857878]

Lankenau SE, Teti M, Silva K, Bloom JJ, Harocopos A, Treese A. Initiation into prescription opioid misuse amongst young injection drug users. Int. J. Drug Policy. 2012; 23:37-44. [PubMed: 21689917]

Lazarsfeld, P.; Henry, N. Latent Structure Analysis. New York: Houghton Mifflin; 1968.

Magidson, J.; Vermunt, J. Latent class models. In: Kaplan, D., editor. The SAGE Handbook of Quantitative Methodology for the Social Sciences. Thousand Oaks, CA: Sage Publications; 2004. p. 345-368.

Manchikanti L, Fellows B, Ailinani H, Pampati V. Therapeutic use, abuse, and nonmedical use of opioids: a ten-year perspective. Pain Physician. 2010; 13:401-435. [PubMed: 20859312]

McCabe SE, Boyd CJ, Teter CJ. Subtypes of nonmedical prescription drug misuse. Drug Alcohol Depend. 2009; 102:63-70. [PubMed: 19278795]

Monga N, Rehm J, Fischer B, Brissette S, Bruneau J, El-Guebaly N, Noel L, Tyndall M, Wild C, Leri F, Fallu JS, Bahl S. Using latent class analysis (LCA) to analyze patterns of drug use in a population of illegal opioid users. Drug Alcohol Depend. 2007; 88:1-8. [PubMed: 17049753] 
Muthén, LK.; Muthén, BO. Mplus User's Guide. Sixth Edition.. Los Angeles, CA: Muthén and Muthén; 2012.

Passik SD, Hays L, Eisner N, Kirsh KL. Psychiatric and pain characteristics of prescription drug abusers entering drug rehabilitation. J. Pain Palliat. Care Pharmacother. 2006; 20:5-13. [PubMed: 16702131]

Paulozzi LJ, Ryan GW. Opioid analgesics and rates of fatal drug poisoning in the United States. Am. J. Prev. Med. 2006; 31:506-511. [PubMed: 17169712]

Peavy KM, Banta-Green CJ, Kingston S, Hanrahan M, Merrill JO, Coffin PO. "Hooked on" prescription-type opiates prior to using heroin: results from a survey of syringe exchange clients. J. Psychoactive Drugs. 2012; 44:259-265. [PubMed: 23061326]

Robins, L.; Cottler, L.; Bucholz, K.; Compton, W. National Institute of Mental Health Diagnostic Interview Schedule for DSM-IV. St. Louis, MO: Washington University Department of Psychiatry; 1999.

Siegal HA, Falck RS, Carlson RG, Wang J, Rahman AM. Health services research among crackcocaine users: a case study from the midwest. Am. Behav. Sci. 1998; 41:1063-1078.

Siegal HA, Carlson RG, Kenne DR, Swora M. Probable relationship between opioid abuse and heroin use. Am. Fam. Physician. 2003; 67:943-944.

Simoni-Wastila L, Ritter G, Strickler G. Gender and other factors associated with the nonmedical use of abusable prescription drugs. Subst. Use Misuse. 2004; 39:1-23. [PubMed: 15002942]

Substance Abuse and Mental Health Services Administration. Rockville, MD: NSDUH Series H-41, HHS Publication No. SMA 11-4658; 2011. Results from the 2010 National Survey on Drug Use and Health: Summary of National Findings.

Surratt HL, Inciardi JA, Kurtz SP. Prescription opioid abuse among drug-involved street-based sex workers. J. Opioid Manag. 2006; 2:283-289. [PubMed: 17319260]

Vaughn MG, Fu Q, Perron BE, Wu LT. Risk profiles among adolescent nonmedical opioid users in the United States. Addict. Behav. 2012; 37:974-977. [PubMed: 22525786]

Vermunt JK. Latent class modeling with covariates: two improved three-step approaches. Polit. Anal. 2010; 18:450-469.

Wang J, Carlson RG, Falck RS, Siegal HA, Rahman A, Li L. Respondent-driven sampling to recruit MDMA users: a methodological assessment. Drug Alcohol Depend. 2005; 78:147-157. [PubMed: 15845318]

Wang J, Falck R, Li L, Rahman A, Carlson RG. Respondent-driven sampling in the recruitment of illicit stimulant drug users in a rural setting: findings and technical issues. Addict. Behav. 2007; 32:924-937. [PubMed: 16901654]

Webster LR, Cochella S, Dasgupta N, Fakata KL, Fine PG, Fishman SM, Grey T, Johnson EM, Lee LK, Passik SD, Peppin J, Porucznik CA, Ray A, Schnoll SH, Stieg RL, Wakeland A. An analysis of the root causes for opioid-related overdose deaths in the United States. Pain Med. 2011; 12:s26s35. [PubMed: 21668754]

Wu LT, Woody GE, Yang C, Blazer DG. Subtypes of nonmedical opioid users: results from the national epidemiologic survey on alcohol and related conditions. Drug Alcohol Depend. 2010; 112:69-80. [PubMed: 20580168]

Yaksh, TL.; Wallace, MS. Opioids, analgesia, and pain management. In: Brunton, LL.; Chabner, BA.; Knollmann, B., editors. Goodman and Gillman's the Pharmacological Basis of Therapeutics. 12th edition.. New York: McGraw Hill; 2011. p. 481-525.

Zacny J, Bigelow G, Compton P, Foley K, Iguchi M, Sannerud C. College on Problems of Drug Dependence taskforce on prescription opioid non-medical use and abuse: position statement. Drug Alcohol Depend. 2003; 69:215-232. [PubMed: 12633908]

Zacny JP, Lichtor SA. Nonmedical use of prescription opioids: motive and ubiquity issues. J. Pain. 2008; 9:473-486. [PubMed: 18342577] 


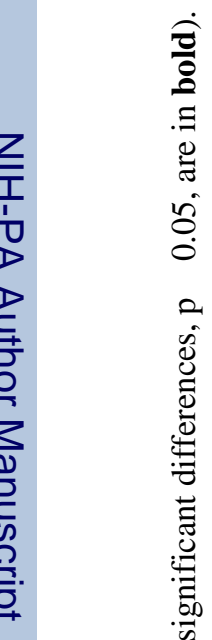

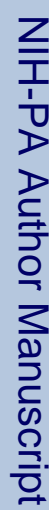

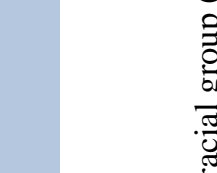

Z

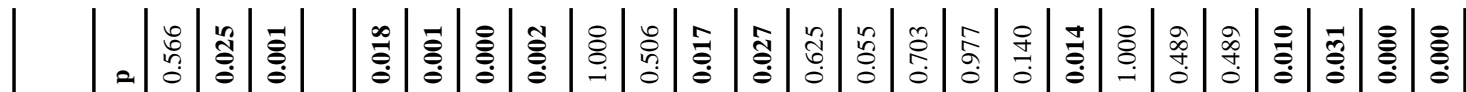

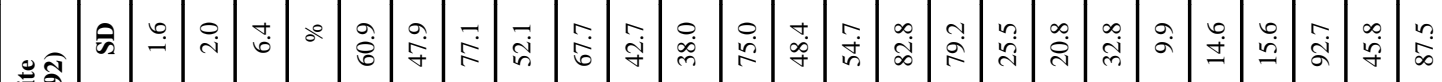

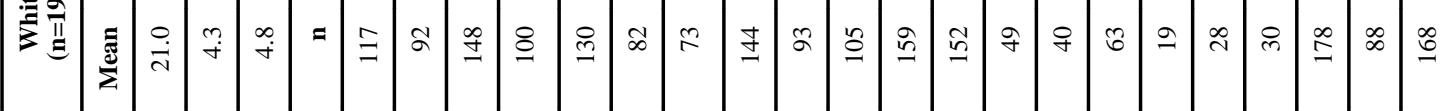

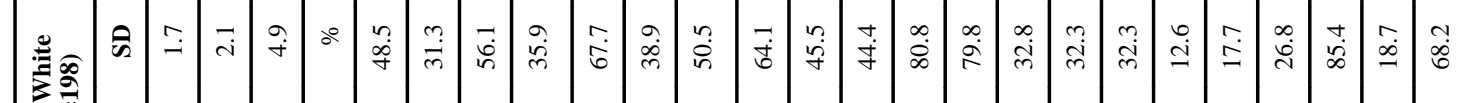
हो की

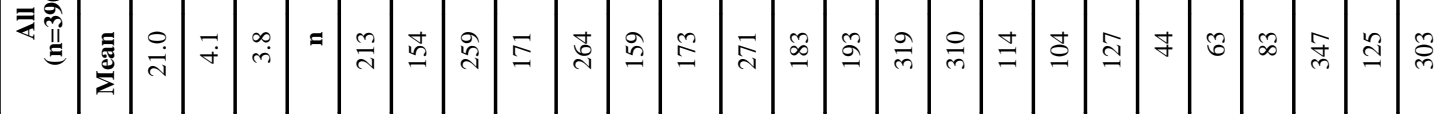




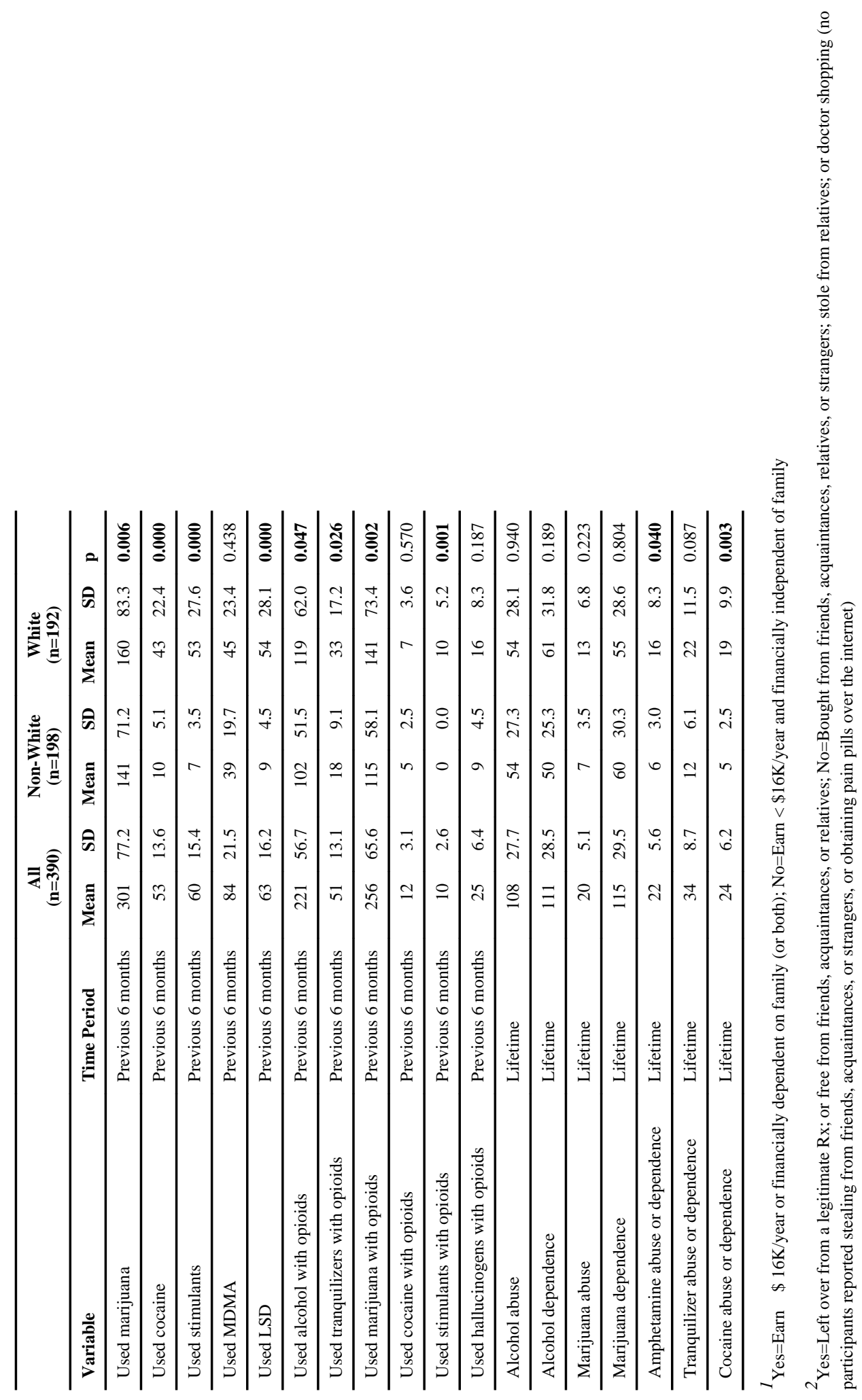




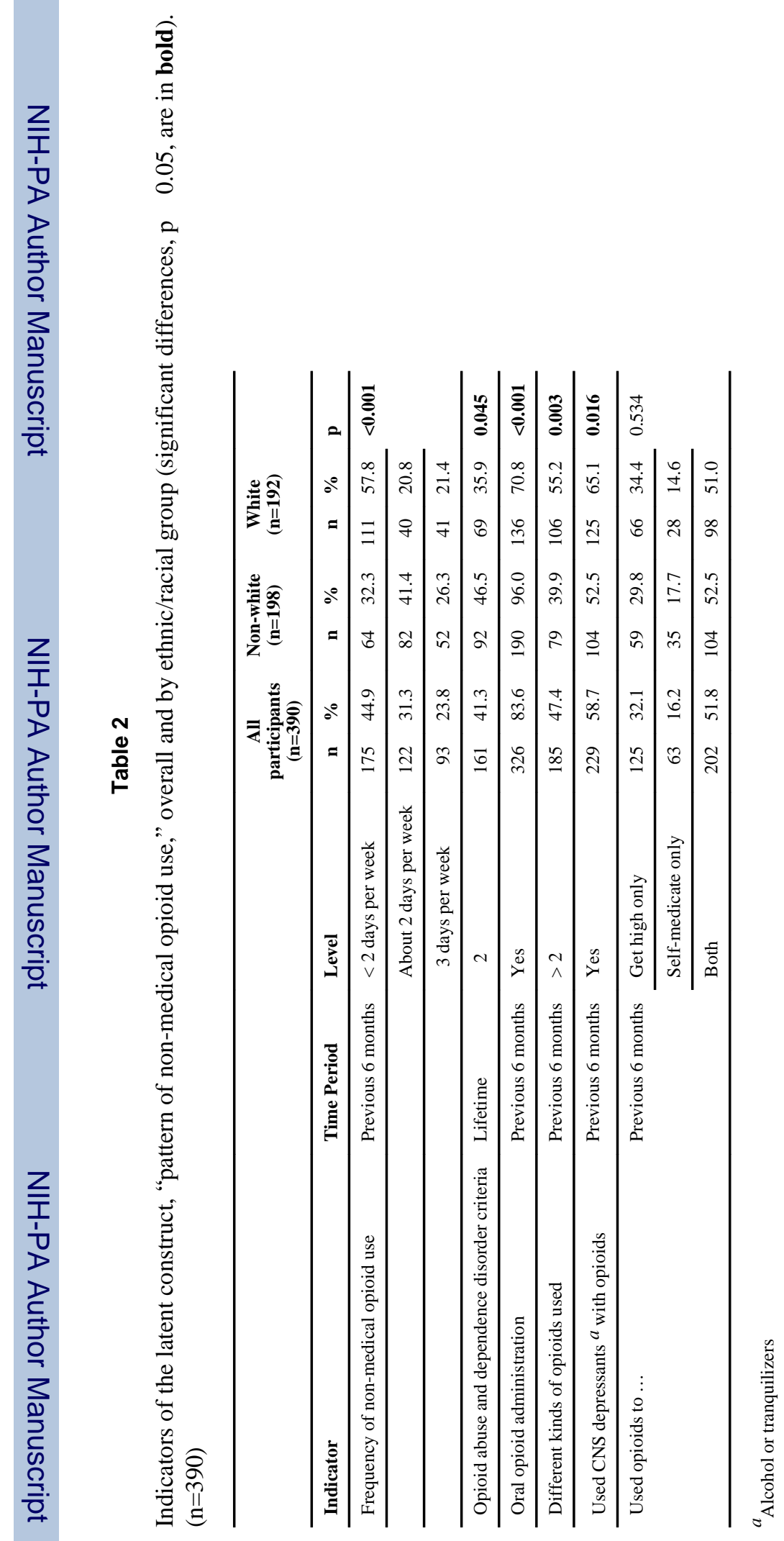




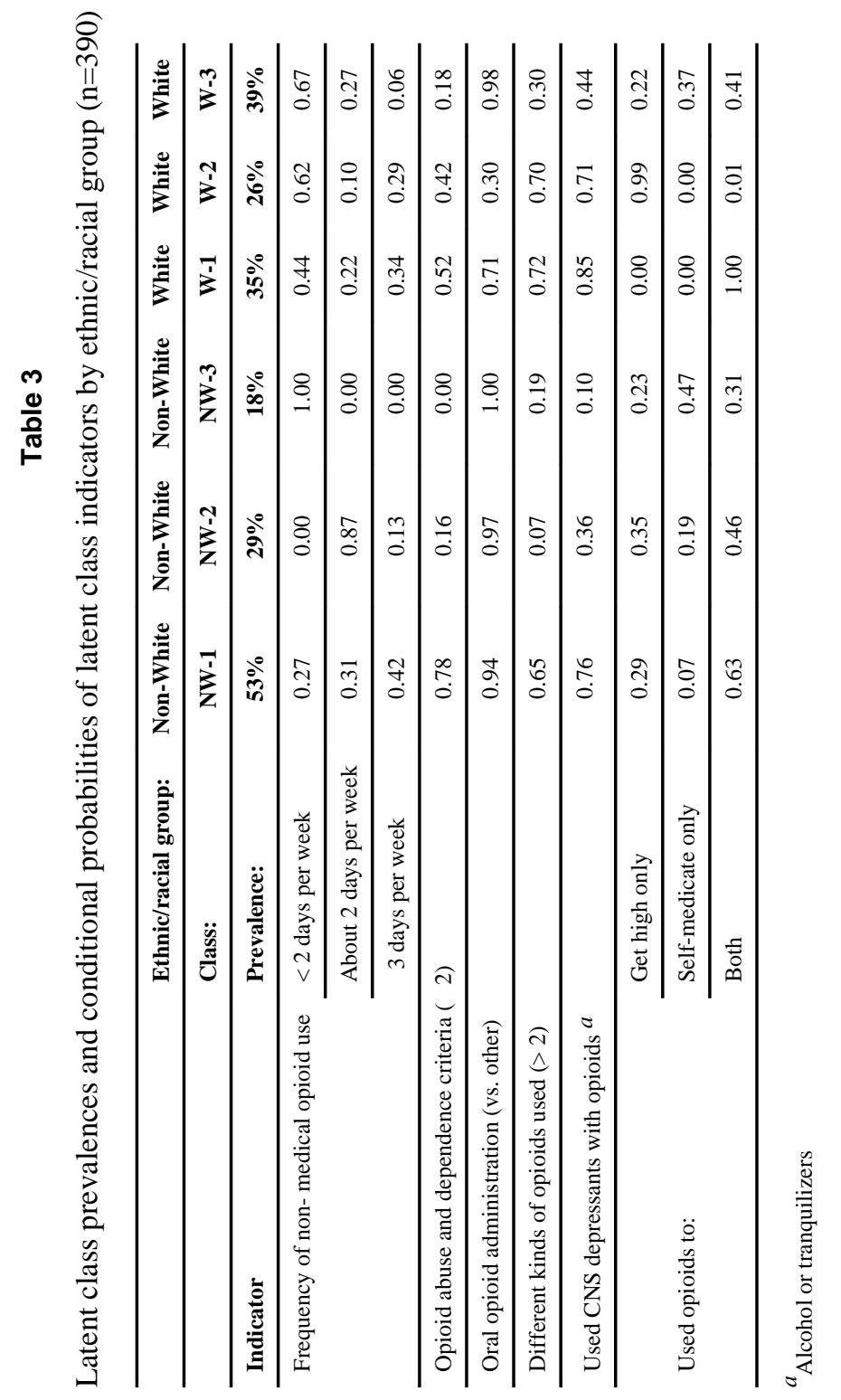




\section{Table 4}

Odds ratios (95\% confidence intervals) for significant predictors of latent class membership (significant odds ratios, $\mathrm{p} \leq 0.05$, are in bold; all significant predictors (covariates) are in the model simultaneously).

\begin{tabular}{lccc}
\hline Variable & NW-1 vs. NW-2 & NW-1 vs. NW-3 & NW-2 vs. NW-3 \\
\hline Age (years) & $\mathbf{1 . 2 7}(\mathbf{1 . 0 1}, \mathbf{1 . 6 0})$ & $\mathbf{1 . 3 2}(\mathbf{1 . 0 1}, \mathbf{1 . 7 2})$ & $1.04(0.78,1.37)$ \\
\hline & W-1 vs. W-2 & W-1 vs. W-3 & W-1 vs. W-3 \\
\hline Age (years) & $\mathbf{1 . 3 1}(\mathbf{1 . 0 0}, \mathbf{1 . 7 0})$ & $1.04(0.77,1.42)$ & $0.80(0.61,1.04)$ \\
\hline Education (Some college) & $0.77(0.33,1.81)$ & $1.96(0.81,4.78)$ & $\mathbf{2 . 5 5}(\mathbf{1 . 0 1}, \mathbf{6 . 4 6})$ \\
\hline
\end{tabular}




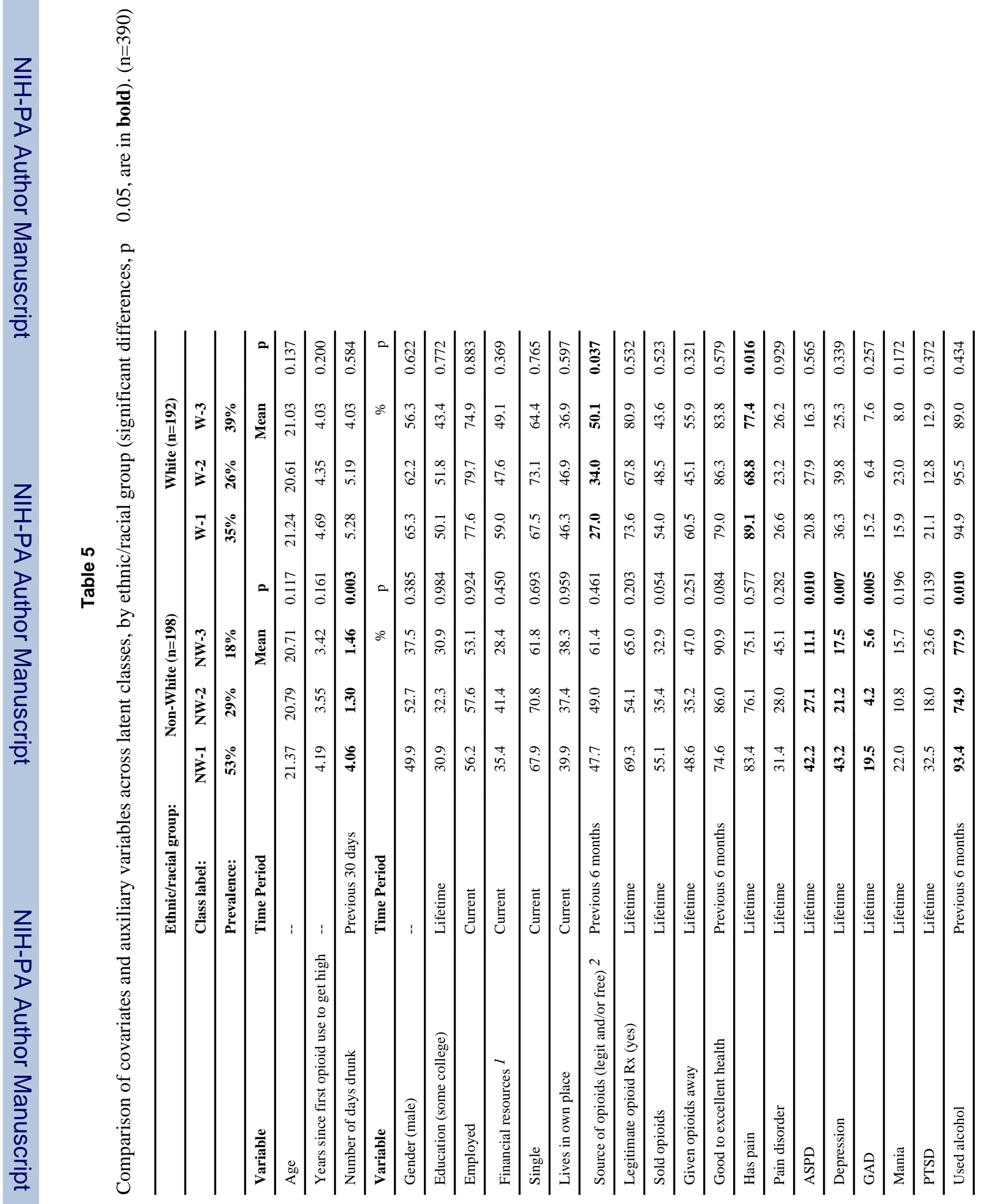




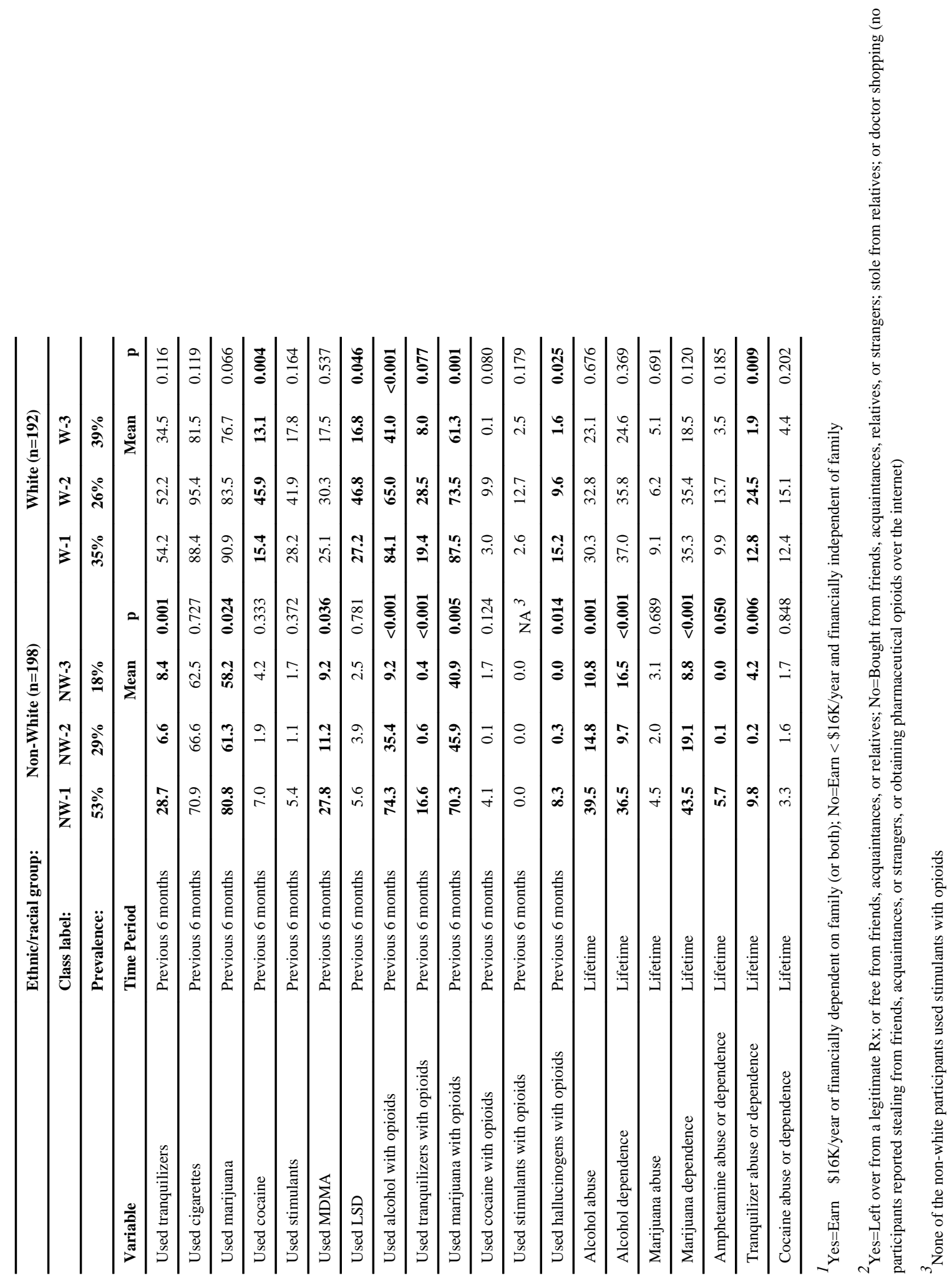

